\title{
EL $t r n L-t r n F$ DE cpADN CONTRIBUYE A LA SEPARACIÓN DE LOS SUBGÉNEROS Persea y Eriodaphne (Lauraceae; Persea) COMO GÉNEROS INDEPENDIENTES
}

\section{THE cpDNA trnL-trnF CONTRIBUTES TO THE SEPARATION OF THE SUBGENERA Persea and Eriodaphne (Lauraceae; Persea) AS INDEPENDENT GENERA}

\author{
Cecilia Cabrera-Hernández ${ }^{1}$, Ernestina Valadez-Moctezuma ${ }^{1}$, María Edith Cruz-Maya ${ }^{1}$, Lily X. \\ Zelaya-Molina ${ }^{2}$, Alejandro F. Barrientos-Priego ${ }^{{ }^{*}}$, Juan Carlos Reyes-Alemán ${ }^{3}$
}

${ }^{1}$ Posgrado en Horticultura, Departamento de Fitotecnia, Universidad Autónoma Chapingo. Km 38.5 carretera México-Texcoco, Chapingo, Estado de México, C.P. 56230, México.

${ }^{2}$ Centro Nacional de Recursos Genéticos, Instituto Nacional de Investigaciones Forestales, Agrícolas y Pecuarias. Av. Biodiversidad No. 2498. Col. Centro. Tepatitlán de Morelos, Jalisco, CP. 47600, México.

${ }^{3}$ Centro Universitario UAEM Tenancingo, Universidad Autónoma del Estado de México. Carretera Tenancingo-Villa Guerrero km 1.5. Tenancingo, Estado de México, C.P. 52400, México.

* Autor de correspondencia E-mail: abarrien@correo.chapingo.mx; abarrien@gmail.com

\section{RESUMEN}

El género Persea tiene dos subgéneros, Persea y Eriodaphne. Existe controversia sobre la taxonomía entre las especies del subgénero Persea y su relación con el subgénero Eriodaphne. Debido a sus complejos patrones evolutivos, el subgénero Persea tiene considerable variabilidad con afinidades taxonómicas inciertas. En este estudio se analizaron las secuencias de la región $t r n L-t r n F$ de DNA de cloroplastos, obtenidos de hojas de 38 accesiones, siete del subgénero Eriodaphne y 31 del subgénero Persea, además uno de Beilschmiedia. Un primer alineamiento con el espacio intergénico trnL-trnF, incluyó 12 individuos del género Persea y uno del género Beilschmiedia, que se alinearon con 26 secuencias del GenBank de 22 géneros de la familia Lauraceae y un género de la familia Hernandiaceae. En un segundo alineamiento con un fragmento de aproximadamente 900 pb que comprende el extremo $3^{\prime}$ del gen $t r n L_{u a a}$ que incluye un intron, el espaciador $t r n L-F$ y el extremo 5' del gel trnF ${ }_{\text {gaa }}$ se incluyó cuatro secuencias del GenBank, una de Persea americana (AY841669), y tres especies del género Sassafras. Lo anterior con el objetivo de inferir sus posibles relaciones filogenéticas y en especial la de los dos subgéneros. El análisis filogenético no fue congruente con la clasificación actual del género, donde se separó fuertemente los dos subgéneros Persea y Eriodaphne, mientras que el clado del subgénero Persea no mostró una agrupación por raza, al igual que por afinidad de especies. Lo encontrado soporta la hipótesis de que los subgéneros Persea y Eriodaphne deben considerarse como géneros independientes.

Palabras clave: aguacate, aguacatillo, Persea, Eriodaphne, clasificación taxonómica, filogenia, espacio intergénico 


\section{ABSTRACT}

The genus Persea has two subgenera, Persea and Eriodaphne. There is controversy about the taxonomy between species of the subgenus Persea, and its relationships with the subgenus Eriodaphne. Because of its complex evolutionary patterns, the subgenus Persea has considerable variability with uncertain taxonomic affinities. In this study, we analyzed the sequences of the trnLtrnF region of chloroplast DNA from leaves of 38 accessions: 7 of the subgenus Eriodaphne and 31 from the subgenus Persea; one accession of the subgenus Beilschmiedia was also included. The first alignment with the trnL-trnF intergenic spacer included 12 individuals of the genus Persea and one of Beilschmiedia, which were aligned with 26 sequences from the GenBank of 22 genera of the Lauraceae family and one of the Hernandiaceae family. In a second alignment with a fragment close to $900 \mathrm{pb}$ that comprises the end $3^{\prime}$ of the $\operatorname{trn} L_{\text {uaa }}$ gene, which includes an intron, the $\operatorname{trnL}-F$ spacer and the end $5^{\prime}$ of the $t r n F_{\text {gaa }}$ gene, four sequences from the GenBank were included: one of Persea americana (AY841669), and three species of the genus Sassafras. The aim of this study was to infer the possible phylogenetic relationships, particularly those of the two subgenera. The phylogenetic analysis was not consistent with the current classification of the genus as it clearly separated the two subgenera Persea and Eriodaphne, while in the clade of subgenus Persea did not show species grouping or affinity. The findings of this study support the hypothesis that the subgenera Persea and Eriodaphne should be regarded as independent genera.

Key words: avocado, "aguacatillo", Persea, Eriodaphne, taxonomic classification, phylogeny, intergenic spacer

\section{INTRODUCCIÓN}

El género Persea comprende alrededor de 150 especies de árboles perennifolios que se distribuyen principalmente desde el sur de los Estados Unidos de Norteamérica hasta Chile. El género se ha divido, con base a diversas características morfológicas, en los subgéneros Persea y Eriodaphne (Kopp, 1966; van der Werff, 2002), siendola pubescencia dela carainterior delos tépalos y el tamaño de los frutos las características principales para diferenciar ambos subgéneros. Persea tiene ambas caras pubescentes y frutos grandes conocidos como aguacates verdaderos, y Eriodaphne presenta frutos pequeños, llamados aguacatillos, y generalmente, la cara interna sin pubescencia (Barrientos-Priego y LópezLópez, 2000). La especie más representativa del género y subgénero Persea es Persea americana Mill., comúnmente conocida como aguacate, el cual es un frutal de gran importancia agrícola y económica a nivel mundial (Schaffer et al., 2013).

La conservación del aguacate es de gran importancia para poder enfrentar los posibles problemas de la industria aguacatera en el futuro (Barrientos-Priego, 1999), donde los bancos de germoplasma en México han tratado de mantener la diversidad existente en el género Persea (Barrientos, 2010). Es de importancia conocer las relaciones filogenéticas y aspectos taxonómicos de las diferentes accesiones conservadas, con el fin de poder tomar decisiones en los bancos de germoplasma y para poder orientar futuras colectas, además de poder delimitar acciones respecto al mejoramiento genético (FAO, 2011).

Los intentos de poder incorporar o combinar en $P$. americana características agronómicas de especies pertenecientes al subgénero Eriodaphne (con excepción de $P$. longipes), por medio de injertos o híbridos, pusieron de manifiesto la incompatibilidad vegetativa (Frolich et al., 1958) y gamética que existe entre los dos subgéneros; donde se consideró que $P$. americana si tiene compatibilidad vegetativa (Frolich et al., 1958) y gamética con otras especies pertenecientes al subgénero Persea (Ellstrand et al., 1986; Bringhurst, 1954). Una de las explicaciones que se ha dado a esta incompatibilidad son las diferencias en el número de ploidía de las especies de ambos subgéneros, pero hasta ahora solo se conoce el número cromosómico de 10 especies de ambos subgéneros que resultaron ser diploides, $2 \mathrm{n}=24$, y solamente una especie tetraploide, $P$. hintonii (García, 1975). Con base a un estudio cladístico sobre caracteres morfológicos Campos-Rojas et al. (2007) proponen que el género Persea es un grupo parafilético y no monofilético, por lo que los subgéneros Persea y Eriodaphne pueden ser reconocidos como géneros independientes.

Es evidente que las relaciones filogenéticas entre las diferentes especies del género Persea son muy complejas y generan controversias durante la delimitación del género (Chanderbali et al., 2001), por lo que aún se encuentra en debate la distinción y separación taxonómica entre los dos subgéneros de Persea, y es necesario que nuevos estudios puedan proporcionar evidencias más precisas que aclaren la filogenia del género. 
Los estudios basados en marcadores de DNA (Ellstrand et al., 1986; Furnier et al., 1990; Clegg, 1993; Ashworth y Clegg, 2003) han proporcionado poca evidencia sobre las relaciones de ambos subgéneros y en otros estudios más recientes las relaciones no son tan claras (Reyes-Alemán et al., 2013; Gutiérrez-Diez et al., 2015; ReyesAlemán et al., 2016). Sin embargo, Rohwer et al. (2009) mediante el análisis de secuencias de la región del ITS de Persea (subgéneros Persea y Eriodaphne) pudieron diferenciar perfectamente el agrupamiento de las especies del subgénero Persea, con los géneros Phobe, Alseodaphne y Dehaasia; mientras que las especies del subgénero Eriodaphne se distribuyeron en forma completamente independiente, lo cual también encontró Li et al. (2011), a utilizar ITS + el intrón LEAFY II. Lo anterior apoya la hipótesis de Campos-Rojas et al. (2007) del origen parafilético del género Persea. Sin embargo, aún hace falta el análisis de más secuencias que puedan apoyar estos resultados.

Uno de los marcadores de cpDNA más utilizados en estudios filogenéticos de plantas es la región trnL-trnF (Taberlet et al., 1991; Pirie et al., 2007), la cual permite inferir relaciones filogenéticas y de tipo evolutivas (Pirie et al., 2007). Esta región consiste de dos genes de tRNA: trn $L_{\text {uaa }^{\prime}}$ y $\operatorname{trnF} F_{\text {gaa }^{\prime}}$ separados por una región no codificante, el espaciador trnL-trnF y un intron cerca del extremo 3' del gen trnL (Pirie et al., 2007). Para el caso de la región trnL-trnF en Lauraceae se encontró poca variación entre las especies de Persea analizadas; una del subgénero Persea y cuatro del subgénero Eriodaphne (Chanderbali et al., 2001), sin embargo, el analizar solo un individuo del subgénero Persea no es concluyente, por lo que es deseable un análisis más cerrado con el subgénero Persea, pero más amplio en cuanto a especies e individuos.

El presente estudio tuvo como objetivo determinar si el marcador de la región trnLtrnF de cpDNA puede llegar a resolver mejor las relaciones filogenéticas dentro del género Persea, y a la vez, apoyar los estudios previos donde se define que los subgéneros Persea y Eriodaphne pueden ser reconocidos como géneros independientes.

\section{MATERIALES Y MÉTODOS}

\section{Material vegetal}

El material vegetal de 38 especies del género Persea (siete del subgénero Eriodaphne y 31 del subgénero Persea) y de una especie del género Beilschmiedia, se obtuvo de la colección del banco de germoplasma de la Fundación Sánchez ColínCICTAMEX, S.C (ubicado en Coatepec Harinas,
México), y de ejemplares depositados en el Herbario de la División de Ciencias Forestales de la Universidad Autónoma Chapingo (CHAP). Los ejemplares son de varias localidades de México y de otros países donde se distribuye este género (Tabla 1).

\section{Extracción, amplificación y secuenciación de ADN}

El ADN se extrajo de $\sim 50-100 \mathrm{mg}$ de hojas previamente deshidratadas en sílica gel; en algunos casos se utilizaron hojas de especímenes deherbario. El ADN genómico se extrajo siguiendo el método de bromuro de hexadeciltrimetilamonio $(\mathrm{CTAB})$, con la modificación que al final del procedimiento el ADN se purificó con columnas QIAquick (Qiagen, Valencia, California, USA) siguiendo las instrucciones del fabricante, esto para eliminar de las muestras la mayor cantidad posible de compuestos fenólicos (Weising et al., 1995).

La amplificación de la región trnL-trnF se realizó en un volumen total de $25 \mu \mathrm{L}$, que contenía 50-100 ng de DNA, $200 \mu \mathrm{M}$ de la mezcla de dNTP's, 1X Colorless GoTaq Flexi Reaction Buffer (Promega, USA), $20 \mathrm{pM}$ de los iniciadores TrnF (5'-AAT TGA ACT GGT GAC ACG AG-3') y TrnL (5'-CGA ATT CGG TAG ACG CTA CG -3') (23), 2,5 mM de $\mathrm{MgCl}_{2}$ y $2 \mathrm{U}$ de GoTaq Flexi DNA Polymerase (Promega, Madison, Wisconsin, USA). El programa de amplificación de los fragmentos consistió en una desnaturalización inicial de $94^{\circ} \mathrm{C}$ por $4 \mathrm{~min}$, seguido de 35 ciclos de $94^{\circ} \mathrm{C}$ por $45 \mathrm{~s}, 61^{\circ} \mathrm{C}$ por $1 \mathrm{~min}, \mathrm{y} 72^{\circ} \mathrm{C}$ por $1 \mathrm{~min}$, finalmente un ciclo de extensión final de $5 \mathrm{~min}$ a $72^{\circ} \mathrm{C}$. Las reacciones de amplificación se llevaron a cabo en un termociclador GeneAmp PCR System 9700 (Applied Biosystems, Foster City, California, USA). Los fragmentos amplificados fueron de aproximadamente 900 pb y se visualizó en un gel de agarosa al 1,2\%. Los productos de PCR se limpiaron de restos de primers y dNTP's no incorporados donde se usó columnas de QIAquick PCR Purification Kit (Qiagen, USA) siguiendo las instrucciones proporcionadas por el fabricante. Los productos de PCR se secuenciaron directamente en ambas direcciones con los primers trnF y trnL, en un sistema de secuenciación automatizado modelo Applied BioSystems 3730XL (Applied BioSystems, USA). Los cromatogramas se editaron y ensamblaron con el programa BioEdit versión 7.0.9.0 (Hall, 1999).

\section{Alineamiento de secuencias}

Las 39 secuencias obtenidas se alinearon con secuencias depositadas en el GenBank (http:// www.ncbi.nlm.nih.gov/genbank/) pertenecientes 
Tabla 1. Especies utilizadas en el análisis, información sobre su registro en el Banco de Germoplasma de la Fundación Salvador Sánchez Colín-CICTAMEX, S.C., del género de Persea y una accesión de Beilschmiedia en el que se han incluido, lugar de colecta y registro en el GenBank.

Table 1. Species used in the analysis, registration information in the Avocado Germplasm Bank of the Fundación Salvador Sánchez Colín-CICTAMEX, S.C., of the genus Persea and one accession of Beilschmiedia , including place of collection and GenBank registration number.

\begin{tabular}{|c|c|c|c|c|}
\hline Taxón & $\begin{array}{l}\text { Clave de } \\
\text { registro }\end{array}$ & Subgénero & Localidad & $\begin{array}{l}\text { Número de } \\
\text { accesión }\end{array}$ \\
\hline Persea americana var. drymifolia & $\mathrm{CH}-\mathrm{C}-63$ & Persea & $\begin{array}{l}\text { Coatepec Harinas, estado de } \\
\text { México, México }\end{array}$ & GU250739 \\
\hline Persea americana var. drymifolia & CH-C-10 & Persea & Tochimilco, Puebla, México & GU250740 \\
\hline Persea americana var. drymifolia & $\mathrm{CH}-\mathrm{C}-57$ & Persea & $\begin{array}{l}\text { Ixtapan del Oro, Edo. de México, } \\
\text { México }\end{array}$ & GU250741 \\
\hline Persea americana var. drymifolia & CH-I-2 & Persea & Guatemala & GU250742 \\
\hline Persea americana var. drymifolia & CH-E-8 & Persea & Ecuador & GU250743 \\
\hline Persea americana var. drymifolia & CH-Der-2 & Persea & $\begin{array}{l}\text { Coatepec Harinas, estado de } \\
\text { México, México }\end{array}$ & GU250744 \\
\hline Persea americana var. americana & CH-I-6 & Persea & La Antigua, Veracruz, México & GU250745 \\
\hline Persea americana var. guatemalensis & CH-G-11 S1 & Persea & Olanca, Chiapas, México & GU250746 \\
\hline Persea schiedeana & CH-Der-1 & Persea & Orizaba, Veracruz, México & GU250747 \\
\hline Persea parvifolia & CH-Ve-2 & Persea & Chocamán, Veracruz, México & GU250748 \\
\hline Persea americana var. guatemalensis & CH-GU-6 & Persea & Guatemala & GU250749 \\
\hline Persea steyermarkii & CH-G-Ch1 & Persea & $\begin{array}{l}\text { San Cristóbal de las Casas, } \\
\text { Chiapas, México }\end{array}$ & GU250750 \\
\hline Persea nubigena & CH-G-76 & Persea & El Rodeo, Siltepec, Chiapas, México & GU250751 \\
\hline Persea steyermarkii & CAV1 & Persea & Tenejapa, Chiapas, México & GU250752 \\
\hline Persea sp. 'Freddy $4^{\prime}$ & CH-CR-29 & Persea & Costa Rica & GU250753 \\
\hline Persea americana var. costaricensis & CH-CR-25 & Persea & Costa Rica & GU250754 \\
\hline Persea schiedeana & CH-H-5 & Persea & Honduras & GU250755 \\
\hline Persea chamissonis & $\mathrm{CH}-\mathrm{Ve}-1$ & Eriodaphne & Huatusco, Veracruz, México & GU250756 \\
\hline Persea lingue & $\mathrm{CH}-\mathrm{Pl}-1$ & Eriodaphne & Chile & GU250757 \\
\hline Persea cinerascens & $\mathrm{CH}-\mathrm{C}-30$ & Eriodaphne & Tacámbaro, Michoacán, México & GU250759 \\
\hline Persea longipes & CH-G-36 & Eriodaphne & $\begin{array}{l}\text { Sierra de Tantima, Veracruz, } \\
\text { México }\end{array}$ & GU250760 \\
\hline Persea sp. 'PR' & CH-PR-1 & Eriodaphne & Veracruz, México & GU250761 \\
\hline Persea chamissonis & $\mathrm{C} 1^{*}$ & Eriodaphne & La Mojonera, Hidalgo, México & GU250763 \\
\hline Persea vesticula & CAV3 & Eriodaphne & Tenejapa, Chiapas, México & GU250764 \\
\hline Persea americana var. costaricensis & $\mathrm{CH}-\mathrm{CR}-44$ & Persea & Costa Rica & GU250765 \\
\hline Persea schiedeana & CH-Gu-1 & Persea & Guatemala & GU250766 \\
\hline Persea americana var. americana & CH-G-48 & Persea & Tetiz, Yucatán, México & GU250767 \\
\hline Persea americana var. guatemalensis & & & & \\
\hline x var. drymifolia & Punta A+T46 & 6 Persea & California, USA (cultivar Hass) & GU250768 \\
\hline Persea americana var. americana & CH-G-45 & Persea & Hunucmá, Yucatán, México & GU250769 \\
\hline Persea americana var. americana & CH -CR- 28 & Persea & Costa Rica & GU250771 \\
\hline Persea americana var. guatemalensis & CH-GU-5 & Persea & Guatemala & GU250772 \\
\hline Persea nubigena & $\mathrm{CH}-\mathrm{I}-4$ & Persea & Guatemala & GU250773 \\
\hline Persea schiedeana $\times$ Persea americana & & & & \\
\hline $\begin{array}{l}\text { var. guatemalensis } \\
\text { Persea americana var. drymifolia }\end{array}$ & $\begin{array}{l}\mathrm{CH}-\mathrm{C}-62 \\
\mathrm{CH}-\mathrm{C}-47\end{array}$ & $\begin{array}{l}\text { Persea } \\
\text { Persea }\end{array}$ & $\begin{array}{l}\text { Guatemala } \\
\text { Tacámbaro Michoa }\end{array}$ & $\begin{array}{l}\text { GU250774 } \\
\text { GU250775 }\end{array}$ \\
\hline Persea americana var. guatemalensis & CH-G-7 S2 & Persea & $\begin{array}{l}\text { San Cristóbal de las Casas, } \\
\text { Chiapas, México }\end{array}$ & GU250776 \\
\hline Persea schiedeana & $\mathrm{CH}-\mathrm{H}-7$ & Persea & Honduras & GU250777 \\
\hline Persea tolimanensis & Mv1 & Persea & Motozintla, Chiapas, México & GU250778 \\
\hline Persea floccosa & CH-I-3 & Persea & Aquila, Veracruz, México & GU250780 \\
\hline Beilschmiedia anay & CG-Hu-56 & - & Cuetzalan, Puebla, México & GU250781 \\
\hline
\end{tabular}

* Material de ejemplares depositados en el Herbario de la División de Ciencias Forestales de la Universidad Autónoma Chapingo (CHAP). 
a la familia Lauraceae. No obstante, al observar que la mayoría de estas secuencias únicamente comprenden el espacio intergénico trnL-trnF, se realizó dos diferentes alineamientos. En el primer alineamiento solamente se consideró el espacio intergénico trnL-trnF, incluyendo 13 de las secuencias obtenidas en este estudio, 12 del género Persea y una del género Beilschmiedia (que se utilizó como género contrastante), las cuales se alineó con 26 secuencias del GenBank pertenecientes a 22 géneros de la familia Lauraceae donde se incluyeron los géneros Persea, Machilus, Listsea, Lindera, Laurus, Sassafras, Rhodostemonodaphne, Pleurothyrium, Umbellularia, Ocotea, Cinnamomum, Kubitzkia, Sextonia, Chorocardium, Mezilaurus, Anaueria, Eusideroxylon, Cryptocarya, Endiandra y Beilschmiedia, y Hernandia albiflora de la familia Hernandiaceae, todas pertenecientes al orden de las Laurales. En el segundo alineamiento se consideró un fragmento de aproximadamente $900 \mathrm{pb}$ que comprende el extremo 3' del gen $t r n L_{\text {uaa }}$ que incluye un intron, el espaciador trnL-F y el extremo $5^{\prime}$ del gel $t r n F_{\text {aaa }}$ se incluyeron cuatro secuencias del GenBank, una de Persea americana (AY841669), y tres representantes del género Sassafras: Sassafras albidum (EF491246), Sassafras tzumu (EF491239) y Sassafras randaiense (EF491243). Ambos alineamientos se realizaron con el programa MUSCLE versión 3.8 (Edgar, 2004).

\section{Análisis filogenético}

El análisis filogenético de los dos alineamientos obtenidos se realizó con el método de Máxima parsimonia con el programa PAUP versión 4.0b10 (Swofford, 2002). En el análisis todos los caracteres tuvieron el mismo valor y los espacios vacíos que se presentaron entre las secuencias alineadas se consideraron como datos faltantes. Para encontrar los árboles más parsimoniosos se utilizó una búsqueda heurística con 1000 repeticiones de adición de taxones al azar y un intercambio de bisección y reconexión de árboles; con la opción Multress sólo se guardaron los mejores árboles de cada paso. En el análisis "bootstrap" se realizaron 1000 repeticiones y una búsqueda heurística con las especificaciones mencionadas con anterioridad.

\section{RESULTADOS}

\section{Características de las secuencias}

En el primer análisis, las secuencias no alineadas del espacio intergénico trnL-trnF variaron de 287 a 360 pares de bases, mientras que el alineamiento final del fragmento de las 39 secuencias fue de 415 pares de bases, de las cuales 46 son sitios parsimonio informativos $(11,08 \%)$, dos de ellos corresponden a mutaciones fijas presentes únicamente en el subgénero Eriodaphne, lo que indica que son mutaciones exclusivas de este subgénero.

En el segundo análisis, las secuencias no alineadas de la región $t r n L-t r n F$ variaron de 856 a 915 pares de bases, mientras que el alineamiento final del fragmento, incluyendo las cuatro secuencias incorporadas del GenBank, fue de 963 caracteres, de los cuales sólo 17 (1,87\%) fueron parsimonio-informativos, cuatro de estos sitios $(0,42 \%)$ agruparon a las especies del subgénero Eriodaphne en un solo clado, dos de ellas son las mencionadas anteriormente para el espacio intergénico trnL-trnF; presentándose así cuatro mutaciones fijas en las especies de este subgénero en esta región (Fig. 1).

Las secuencias dentro del subgénero Persea tuvieron una variación de $0-4,8 \%$, una de las secuencias que presentó el valor más alto de variación con el resto de secuencias fue Persea schiedeana $\mathrm{CH}-\mathrm{H}-7$. En el subgénero Eriodaphne las secuencias fueron prácticamente iguales, únicamente $P$. cinerascens $\mathrm{CH}-\mathrm{C}-30$ presenta una sola base diferente con las otras seis secuencias $(0,11 \%)$. Entre los dos subgéneros la divergencia varió de $0,6 \%$ entre $P$. parvifolia $\mathrm{CH}-\mathrm{Ve}-2$ y $P$. chamissonis CH-Ve-1 a 4,9\% entre Persea floccosa $\mathrm{CH}-\mathrm{I}-3$ y $P$. cinerascens $\mathrm{CH}-\mathrm{C}-30$. El género Sassafras tuvo una variación de $0,3-5,5 \%$ con el subgénero Persea, y de 0,6-2,1\% con el subgénero Eriodaphne. El género Beilschmiedia tuvo una divergencia de $13,4-16,9 \%$ con el subgénero Persea, 13,9-14,0\% con el subgénero Eriodaphne, y $13,6-14,4 \%$ con el género Sassafras.

\section{Análisis de máxima parsimonia}

En el primer análisis filogenético se obtuvieron 4995 árboles igualmente parsimoniosos, con una longitud de 124 pasos, índice de consistencia (CI) de 0,91, con 0,82 excluyendo los caracteres no informativos, y un índice de retención (RI) de 0,91 . El análisis dio como resultado la separación de los subgéneros Persea y Eriodaphne (Fig. 2), se observaron tres clados, en uno se ubican todas las especies del subgénero Persea junto con Machilus, Lindera, Laurus y Litsea, sin embargo, no está soportado por el análisis "bootstrap"; en el segundo clado se agrupan varios género como Cinnamomum, Sassafras y Ocotea, entre otros, el cual está soportado moderadamente con el análisis "bootstrap", mientras que en el tercer clado se agrupan únicamente las especies del subgénero Eriodaphne, y obtuvo buen soporte del análisis "bootstrap".

El segundo análisis filogenético dio como resultado 36 árboles igualmente parsimoniosos, con una longitud de 62 pasos, índice de 


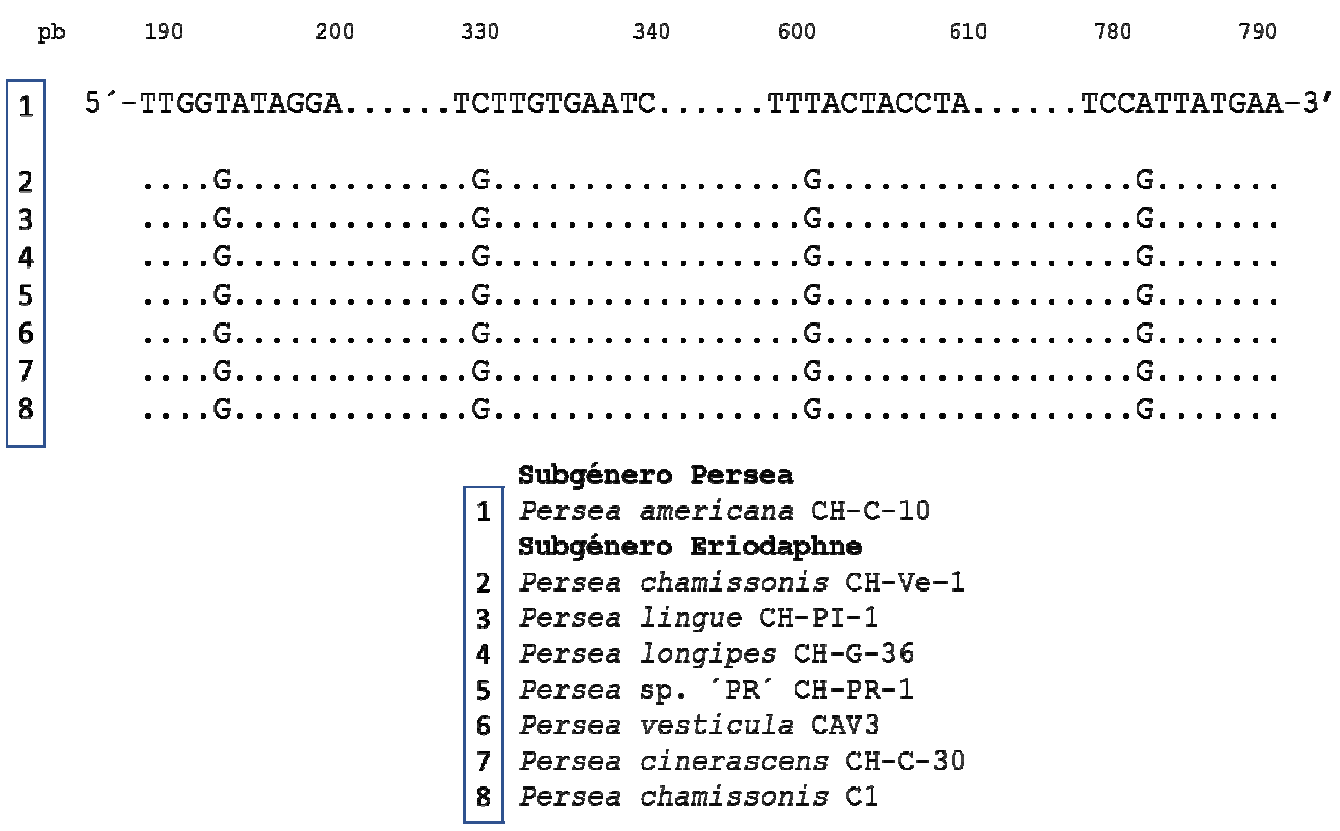

Fig. 1. Ubicación de las mutaciones fijas en el fragmento de 963 pb de la región del trnL-trnF, en las secuencias de las siete especies del subgénero Eriodaphne, donde se consideró como referencia una secuencia del subgénero Persea.

Fig. 1. Location of fixed mutations in the $963 \mathrm{pb}$ fragment of the $t r n L-t r n F$ region, in the sequences of the seven species of the subgenus Eriodaphne, considering a sequence of the subgenus Persea as a reference.

consistencia (CI) de 0,96, con 0,90 excluyendo los caracteres no informativos, y un índice de retención (RI) de 0,96. En árbol dos (Fig. 3), a pesar de la baja resolución que se observó dentro de las especies del subgénero Persea, debido a la poca divergencia que hubo entre las secuencias, se obtuvo que las especies del subgénero Eriodaphne se agruparon en un clado monofilético con un fuerte soporte del análisis "bootstrap" de 99, y aunque el clado se observó emparentado con el género Sasafras, el análisis "bootstrap" no apoya esta relación. Es de resaltar que dentro del subgénero Persea hay otros dos clados agrupados con un alto valor "bootstrap", el más grande formado por siete individuos: seis de Persea americana var. drymifolia y uno de $P$. americana var. americana, el otro grupo está formado por tres individuos: Persea sp. 'Freddy 4' CH-CR-29, Persea schiedeana CH-H-5, y Persea americana var. costaricensis $\mathrm{CH}-\mathrm{CR}-25$.

\section{DISCUSIÓN}

La región trnL-trnF del cloroplasto fue útil para apoyar la definición de la separación de los subgéneros Persea y Eriodaphne, tal como lo planteó morfológicamente Campos-Rojas et al. (2007) y, molecularmente Rohwer et al. (2009) con ITS y Li et al. (2011) con el intrón LEAFY II, además se confirmó que el género Persea es un grupo parafilético y no monofilético (CamposRojas et al., 2007).

Dicha separación de ambos subgéneros fue debida a cuatro mutaciones fijas exclusivas del subgénero Eriodaphne, los cuales pueden ser utilizados para discriminar individuos donde se tenga duda respecto a su ubicación taxonómica, en este caso como se propone a nivel de género (exsubgénero), ya que uno de los grandes problemas en identificación de ejemplares de herbario es que frecuentemente no cuentan con flores o frutos, lo cual dificulta esta labor y conlleva a errores, tal como se ha encontrado en algunos estudios (Lorea-Hernández, 2002; Aguilar-Gallegos et al., 2014).

La divergencia entre secuencias de los dos subgéneros Persea y Eriodaphne (4,9\%) es cercano a la del género Sassafras con el subgénero Persea $(5,5 \%)$, lo cual también soporta la separación de ambos subgéneros. Por otra parte, existen diferencias que también apoyan la separación de ambos subgéneros, tales como la incapacidad de hibridación entre los dos subgéneros (Lahav y Lavi, 2013) y la falta de compatibilidad vegetativa, la cual fue demostrada entre varias de las especies del subgénero Eriodaphne con 


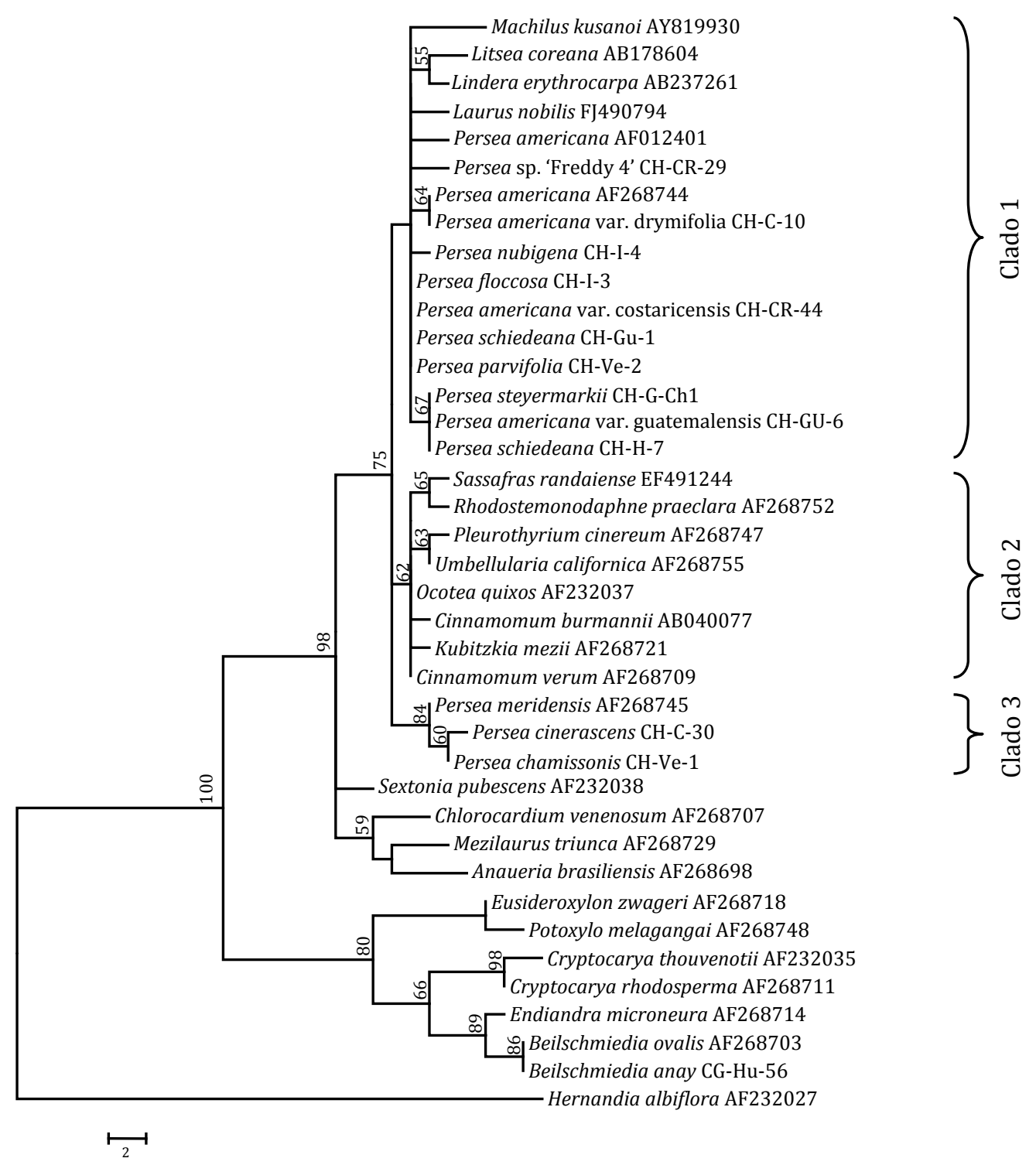

Fig. 2. Árbol filogenético del fragmento intergénico $t r n L-t r n F(415 \mathrm{pb})$ generado con el método de Máxima Parsimonia y 1000 búsquedas heurísticas. El árbol incluye secuencias de 22 géneros de la familia Lauraceae y una de la familia Hernandiacea. Los valores de "bootstrap" > 50 se encuentran en sus respectivas ramificaciones.

Fig. 2. Phylogenetic tree of the trnL-trnF intergenic fragment (415 pb) generated with the Maximum Parsimony method and $\mathbf{1 0 0 0}$ heuristic searches. The tree includes sequences of 22 genera of the Lauraceae family and one of the Hernandiaceae family. Bootstrap values $>50$ are placed on the respective branches.

el subgénero Persea (Frolich et al., 1958). Este aspecto es de gran relevancia para la planeación de futuras colectas y aspectos de conservación de germoplasma de aguacate, ya que se puede pensar que no sería prudente colectar ni conservar especies del subgénero Eriodaphne por estar menos emparentadas con el subgénero Persea del cual pertenece el aguacate, sin embargo, no hay que perder de vista que por lo menos existe una especie del subgénero Eriodaphne que es compatible vegetativamente con el aguacate y que se trata de Persea longipes (Frolich et al, 1958) y es probable que existan otras. Habrá que realizar en cada caso estudios de compatibilidad con el fin de valorar si una accesión deba entrar o no a la conservación en el caso de bancos de 


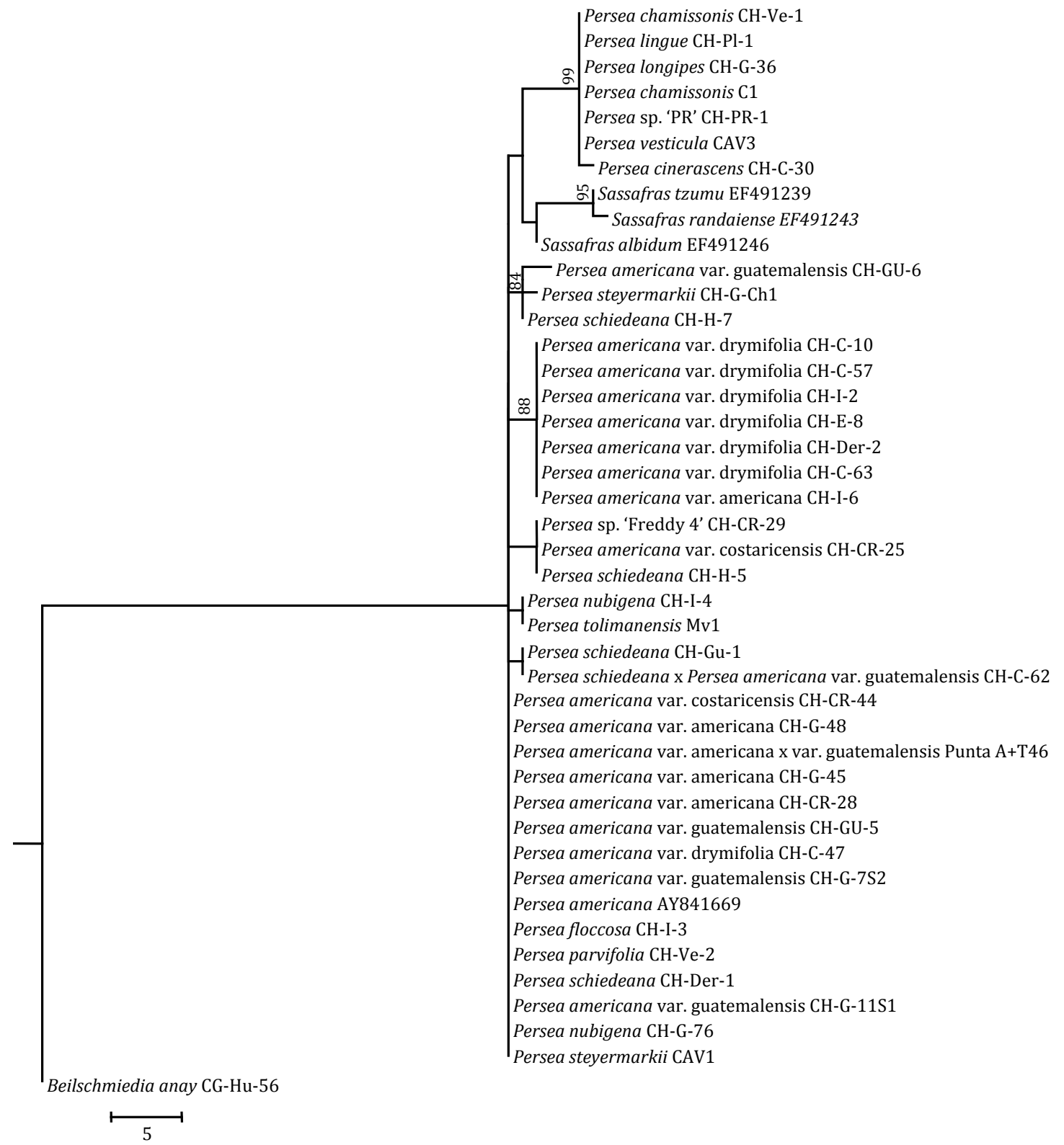

Fig. 3. Árbol filogenético de Persea y Sassafras de la región del trnL-trnF generado con el método de Máxima Parsimonia y 1000 búsquedas heurísticas. Los valores de "bootstrap" > 50 se encuentran en sus respectivas ramificaciones. Beilschmiedia anay fue utilizado para enraizar el árbol.

Fig. 3. Phylogenetic tree of the trnL-trnF region generated with the Maximum Parsimony method and 1000 heuristic searches. Bootstrap values > 50 are placed on their respective branches. Beilschmiedia anay was used to root the tree.

germoplasma de aguacate. Para el caso de su utilización en mejoramiento genético se deben realizar estudios de compatibilidad gamética, ya que hasta el momento se sabe que no existe entre los subgéneros Persea y Eriodaphne (Lahav y Lavi, 2013), sin embargo, existen la posibilidad de realizar fusión de protoplastos entre los dos subgéneros (Litz y Grosser, 1998) y aprovechar la resistencia que existe el subgénero Eriodaphne (Pliego-Alfaro y Bergh, 1992).

El subgénero Eriodaphne se presentó con siete individuos que no mostraron gran divergencia en sus secuencias, donde solo Persea cinerascens mostró cierta diferencia, lo cual también ocurrió con varias especies del subgénero Persea, donde se presentó dos clados con alto valor "bootstrap". 
Esta falta de divergencia dentro del subgénero Persea ya había sido señalada por Mhameed et al. (1997) y Ashworth y Clegg (2003) al usar microsatélites no pudieron agrupar por especies a individuos del subgénero Persea. En otro estudio Gutiérrez-Diez et al. (2015) no encontró separación de los subgéneros Persea y Eriodaphne utilizando 16 microsatélites, que a su vez usaron Alcaraz y Hormaza (2007) en un estudio con variedades de aguacate. Por lo anterior es posible indicar que se requiere estudiar otras secuencias con el fin de dar mayor resolución al mismo, y tal vez realizar análisis concatenados de varias secuencias o genes, tanto de cloroplasto, mitocondria y núcleo, y así de tal manera definir si el subgénero Persea es monofilético como lo propone van der Weff (2002).

\section{CONCLUSIONES}

La región trnL-trnF del cloroplasto separó fuertemente a los subgéneros Persea y Eriodaphne. Lo encontrado en este estudio soporta la hipótesis de que deben considerarse como géneros independientes, y esto es probable debido a que los dos géneros no están muy cercanamente relacionados, como se suponía, lo cual es soportado con el resultado obtenido.

\section{RECONOCIMIENTOS}

Se agradece el apoyo financiero otorgado por la Red de Aguacate del Sistema Nacional de Recursos Fitogenéticos para la Alimentación y la Agricultura (SINAREFI-SNICS-SAGARPA) mediante el proyecto FRU-AGU-09-1.

\section{LITERATURA CITADA}

Aguilar-Gallegos, N., A.F. Barrientos-Priego, M.T. Martínez-Damián, y C.A. Núñez-Colín. 2014. Inventario de ejemplares de herbario de Persea. p. 67-76. En A. Gutiérrez Diez y N. Mayek Pérez (eds.) Los Recursos Genéticos del Aguacatero (Persea spp.) en México, su Estudio, Conservación y Aprovechamiento. Universidad Autónoma de Nuevo León, Monterrey, México.

Alcaraz, M.L., and J.I. Hormaza. 2007. Molecular characterization and genetic diversity in an avocado collection of cultivars and local Spanish genotypes using SSRs. Hereditas 144:244-253.

Ashworth, V.E.T.M., and M.T. Clegg. 2003. Microsatellite markers in avocado (Persea americana Mill.): genealogical relationships among cultivated avocado genotypes. Journal of Heredity 94:407-415.
Barrientos-Priego, A.F. 1999. Conservation of avocado genetic resources in Mexico. Subtropical Fruit News 7(1):1-2.

Barrientos Priego, A.F. 2010. El aguacate. Biodiversitas 88(1):1-7.

Barrientos-Priego, A.F., y L. López-López. 2000. Historia y genética del aguacate. p. 19-31. En D. Téliz, H. González, J. Rodríguez y R. Dromundo (eds.) El aguacate y su manejo integrado. Mundi-Prensa, Distrito Federal, México.

Bringhurst, R. 1954. Interspecific hybridization and chromosome numbers in Persea. Proceedings of the American Society for Horticultural Science 63:239-242.

Campos-Rojas, E., T. Terrazas, and L. LópezMata. 2007. Persea (avocados) phylogenetic analysis based on morphological characters: hypothesis of species relationships. Genetic Resources and Crop Evolution 54:249-258.

Chanderbali, A.S., H. van der Werff, and S.S. Renner. 2001. Phylogeny and historical biogeography of Lauraceae: Evidence from the chloroplast and nuclear genomes. Annals of the Missouri Botanical Garden 88:104-134.

Clegg, M.T. 1993. Chloroplast gene sequences and the study of plant evolution. Proceedings of the National Academy of Sciences of the USA 90:363-367.

Edgar, R.C. 2004. MUSCLE: multiple sequence alignment with high accuracy and high throughput. Nucleic Acids Research 32:17921797.

Ellstrand, C., J. M.E. Lee, B.O. Bergh, M.D. Coffey, and G.A. Zentmyer. 1986. Isozymes confirm hybrid parentage for G 755 selections. California Avocado Society Yearbook 70:199203.

FAO. 2011. Draft updated global plan of action for the conservation and sustainable utilization of plant genetic resources for food and agriculture. 5th Session of the Intergovernmental Technical Working Group on Plant Genetic Resources for Food and Agriculture, 27-29 April 2011. FAO, Rome, Italy.

Frolich, E.F., C.A. Schroeder, and G.A. Zentmyer. 1958. Graft compatibility in the genus Persea. California Avocado Society Yearbook 42:102105.

Furnier, G.R., M. P. Cummings, and M. T. Clegg. 1990. Evolution of the avocados as revealed by DNA restriction fragment variation. Journal of Heredity 81:183-188.

García, A. 1975. Cytogenetical studies in the genus Persea (Lauraceae). I. Karyology of seven species. Canadian Journal of Genetics and Cytology 17:173-180. 
Gutiérrez-Díez, A., A.F. Barrientos-Priego, y E. Campos-Rojas. 2015. Caracterización molecular y análisis filogenético de los subgéneros Persea y Eriodaphne (Lauraceae). p. 88-94. En Actas del VIII Congreso Mundial de la Palta. 13 al 18 de septiembre 2015. Asociación de Productores de Palta de Perú (ProHass), Lima, Perú.

Hall, T. A. 1999. BioEdit: a user-friendly biological sequence alignment editor and analysis program for Windows 95/98/NT. Nucleic Acids Symposium Series 41:95-98.

Kopp, L. E. 1966. A taxonomic revision of the genus Perseae in the Western Hemisphere (Perseae-Lauraceae). Memoirs of the New York Botanical Garden 14:1-120.

Lahav, E. and U. Lavi. 2013. 4 Genetics and breeding. p. 51-85. In B. A. Schaffer, A. W. Whiley, B. N. Wolstenholme (eds.) The avocado: botany, and uses. CAB International Publishing, Oxfordshire, UK.

Li, L., J. Li, J.G. Rohwer, H. van der Werff, Z.H. Wang, and H.W. Li. 2011. Molecular phylogenetic analysis of the Persea group (Lauraceae) and its biogeographic implications on the evolution of tropical and subtropical Amphi-Pacific disjunctions. American Journal of Botany 98(9):1520-1536.

Litz, R.E. and J.W. Grosser, 1998. Isolation, culture and regeneration of avocado (Persea americana Mill.) protoplasts. Plant Cell Reports 18(3-4):235-242.

Lorea-Hernández, F.G. 2002. La familia Lauraceae en el sur de México: diversidad, distribución y estado de conservación. Boletín de la Sociedad Botánica de México 71:59-70.

Mhameed, S., D. Sharon, D. Kaufman, E. Lahav, J. Hillel, C. Degani, and U. Lavi. 1997. Genetic relationships within avocado (Persea americana Mill.) cultivars and between Persea species. Theoretical and Applied Genetics 94:279-286.

Pirie, M.D., V.M.P. Balcazar, M. Botermans, F.T. Bakker, and L.W. Chatrou. 2007. Ancient paralogy in the cpDNA Trnl-F region in Annonaceae: implications for plant molecular systematics. American Journal of Botany 94:1003-1016.
Pliego-Alfaro, F., and B.O. Bergh. 1992. Avocado. p. 323-333. In F.A. Hammerschlag, R.E. Litz (eds.) Biotechnology of perennial fruit crops. CAB Int., Wallingford, UK,

Reyes-Alemán, J.C., E. Valadez-Moctezuma, L. Simuta-Velázco, A.F. Barrientos-Priego, and C. Gallegos-Vázquez. 2013. Distinción de especies del género Persea mediante RAPD e ISSR de ADN. Revista Mexicana de Ciencias Agrícolas 4(4):517-529.

Reyes-Alemán, J.C., E. Valadez-Moctezuma, and A.F. Barrientos-Priego. 2016. Assessment of genetic relationship in Persea spp. by traditional molecular markers. Genetics and Molecular Research 15(2):1-11. http://dx.doi. org/10.4238/gmr.15027359

Rohwer, J.G., J. Li, B. Rudolph, S. Schmidt, H. van der Werff, and H. Li, 2009. Is Persea (Lauraceae) monophyletic? Evidence from nuclear ribosomal ITS sequences. Taxon 58:1153-1167.

Schaffer, B., B.N. Wolstenholme, and A.W. Whiley. 2013. 1 Introduction. p. 1-9. In B. A. Schaffer, A. W. Whiley, B. N. Wolstenholme (eds.) The avocado botany, and uses. CAB International Publishing, Oxfordshire, UK.

Swofford, D. L. 2002. PAUP*: Phylogenetic analysis using parsimony (*and other methods). 142 p. Sinauer Associates, Sunderland, USA.

Taberlet, P., L. Gielly, G. Pautou, and J. Bouvet. 1991. Universal primers for amplification of three non-coding regions of chloroplast DNA. Plant Molecular Biology 17:1105-1109.

van der Werff, H. 2002. A synopsis of Persea (Lauraceae) in Central America. Novon 12:575-586.

Weising, K., H. Nybom, K. Wolff, and W. Meyer. 1995. DNA fingerprinting in plants and fungi. 322 p. CRC Press, Boca Raton, USA. 